Pensamiento Crítico Vol.21, № 2, pp. 37 - 49

\title{
Economía y Literatura: a la luz de narradores asiáticos, europeos y peruanos
}

Economy and Literature: by the light of asian, european narrators and peruvians

[Recepción: Setiembre de 2016 / Conformidad: Octubre de 2016]

Carlos Armas Morales ${ }^{1}$

\section{RESUMEN}

El artículo trata de mostrar la presencia de la economía a través de la investigación bibliográfica de obras literarias (novelas y cuentos) de autores japoneses, franceses y peruanos; en la posibilidad de conocer algunas relaciones de la economía y la narrativa y, asimismo, observar la utilidad de la lectura de estas obras como complemento en la enseñanza de algunas materias de economía (realidad nacional, derecho económico, historia económica del Perú, etc.), de conformidad con los resultados de una investigación del autor.

Palabras clave: Economía y literatura, narrativa y economía.

1 Doctor de Derecho y Ciencia Política (UNMSM), ingeniero industrial (UNI). Docente de la Facultad de Ciencias Económicas (Pre y Posgrado). Docente posgrado Facultad de Ingeniería Electrónica. Difusor científico. Autor de dos libros de ciencia y tecnología y derecho. 


\title{
Pensamiento Crítico Vol. ᄅl, № 2
}

\begin{abstract}
The article tries to show the presence of the economy through the bibliographical investigation of literary works (you novelize and stories) of Japanese, French authors and Peruvians; in the possibility of knowing some relationships of the economy and the narrative one and also to observe the utility of the reading of these works like supplement in the teaching of some matters of economy (national reality, economic right, economic history of the country etc.) of conformity with the results of the author's investigation.
\end{abstract}

Keywords: Economy and literature, narrative and economy.

\section{Introducción}

Expresamos que las disciplinas científicas se direccionan en la actualidad hacia una convergencia interdisciplinaria, como nuevas formas de afrontar los actos científicos, tecnológicos y sociales que, traducido en hechos sociales, influyen y robustecen la fundamentación del saber, avizorando una nueva concepción de aprendizaje, tanto de las ciencias, las letras y las artes, donde se apunta, de acuerdo a este artículo, la economía y la narración literaria. El presente artículos plantea relaciones entre la economía y la narrativa, asimismo procura que esta interrelación involucre a autores de diferentes ámbitos territoriales o continentales para una mayor validez, tal como la narrativa japonesa, francesa y peruana. Es perentorio indicar que el artículo tiene su origen en un trabajo de investigación gestado a partir de la enseñanza actual de los cursos de Derecho Económico y Realidad Nacional por el autor, lo que nos permitió evaluar a la narrativa peruana (novelas y cuentos), con la posibilidad de usarla como complemento para el aprendizaje y enseñanza de estos cursos y otros similares, como Historia Económica del Perú, que se dictan en la Facultad de Ciencias Económicas de la UNMSM. Del estudio observamos que de la narrativa discurren diversos contenidos socioeconómicos y que, pese a ser ficción, esclarecen aspectos que sucedieron en la historia económica del país y que es parte de nuestra realidad.

Las interrelaciones de la economía con la literatura, se puede ver desde dos vertientes: como complemento de explicaciones económicas a sucesos narrativos al servicio del aprendizaje y desde las relaciones teóricas de la economía con la literatura, 


\section{Carlos Armas Morales}

tal como nos muestran diversos autores extranjeros en sendos artículos publicados, a saber: Gallego A, Coordinadora Universidad de Granada, con el artículo Introducción a la literatura y economía, asimismo el artículo de Álvarez Barrientos sobre "Literatura y economía en España", entre otros que han abordado esta temática.

\section{Fundamento teórico de las interacciones de la realidad socioeconómica y la narrativa}

El uso de la narrativa, novelas y cuentos de ficción concordantes con la realidad, tiene diversas formas de fundamentarse, así en la obra El artista y la época, de José Carlos Mariátegui el autor escribe los siguiente: "La experiencia realista no nos ha servido sino para demostrarnos que solo encontramos la realidad por los caminos de la fantasía" (1967, p.23), relievando a la ficción. En otra de sus obras, La novela y la vida, su prologuista Alberto Tauro, suscribe en la nota preliminar, expresa que "...no es posible eludir la cavilación en cuanto intentamos decidir si somos los hombres quienes deseamos emular en la vida a ciertos personajes de novela, o son los novelistas quienes reflejan la pasión de los mortales", en donde se sugiere una indistinción entre la ficción y la realidad. Más recientemente, el profesor sanmarquino Winston Orillo expresa: "que toda literatura autentica, honesta, vive de la realidad -es realidad- $y$, a la vez, la proyecta al plano mítico, inalienable de la ficción" (http://spanish.hanban.org/1985, p.5), donde se conjuga eficientemente la realidad y la ficción.

Desde otro ángulo, hay diversos autores que han referido que para escribir ficción recurren a la historia (realidad formal); así se cuenta que Ciro Alegría, después de la conmoción internacional de su libro El mundo es ancho y ajeno, quiso escribir una novela sobre la conquista. Investigó muchas fuentes históricas de EE.UU., Costa Rica y Cuba, pero cuando ya estaba escribiendo, le llegó una novela del escritor Español

Salvado Madariaga, El corazón de piedra, con similar contenido de fondo, dando finalizado su ambicioso proyecto.

Por esta misma línea y más reciente, el escritor peruano Jorge Eduardo Benavides escribió la novela El enigma del convento, para lo cual se documentó en la Biblioteca Nacional de España para reconstruir la historia de Santa Catalina. 


\section{Pensamiento Crítico Vol. ᄅl, № 2}

Otros escritores peruanos vigentes, tal como Fernando Ampuero en su artículo Revisando La ciudad y los perros, indican que se desplazó la literatura indigenista, imponiendo lo urbano como temática urgente y más atractiva, pues esta ya reflejaba nuestra realidad cardinal de Lima, la gran urbe, que concentra hoy un tercio de la población del país, originadas por supuesto por las olas migratorias del campo a la ciudad (La República 02.12.2012, p.27)

Gustavo Rodríguez (Diario El Comercio 21.08.2015, p. A 25) indica comentando sobre la historia de Mayta de Vargas Llosa: "Quizá sea preciso recordarles a los lectores jóvenes que dicha novela, escrita por Vargas Llosa, muestra los entresijos de una insurrección en la comisaría de Jauja en 1958. En la vida real, sí existió un levantamiento parecido, pero fue en 1963 y estuvo encabezado por un oficial de la Guardia Republicana que contó entre sus lugartenientes al dirigente campesino Humberto Mayta. El Mayta que da nombre a la novela, en cambio, se llama Alejandro".

Entre los extranjeros, el escritor español Giralt indica: "El libro, antes que nada, debe ser literatura, conducido por decisiones literarias, alimentado solo por la vida. La literatura es un intento por comprender el mundo, encajar las piezas de ese rompecabezas que es la realidad, que al madurar intuimos incompletos" (El Comercio 11.12.2015, p.C2).

Asimismo, el escritor nicaragüense Sergio Ramírez alaba como uno de sus maestros al mexicano Carlos Fuentes, pues este le enseñó cómo insertar la historia en mayúscula dentro de la historia ficticia.

No está de más indicar a Roxanee Cheesman (El Comercio - sección A), quien en un artículo periodístico refiere que "las obras literarias cumplen un papel que los mitos tuvieron en la antigüedad, proponiendo soluciones a problemas de la sociedad que no resuelve conscientemente".

El escritor colombiano Pablo Montoya ganó la XIX edición del premio internacional de novela Rómulo Gallegos por su obra Tríptico de la infamia. La novela narra la historia de tres pintores protestantes que se convierten en testigos e intérpretes de los horrores que, en nombre de la religión y el afán de la riqueza, se cometieron en Europa durante el siglo XVI y se extendieron en América recién descubierta" (La República 5 .06.2015, p. 29). 


\section{Carlos Armas Morales}

Todo ello nos indica la presencia y concordancia de la realidad con la ficción, que nos permite asegurar una validez complementaria para la comprensión de temas económico-jurídicos y económico-históricos (derecho económico e historia económica) dentro del aprendizaje, lo que más aún es avalada cuando algunos estudiosos del aprendizaje como Hunter Mc Ewan (compilador), siguiendo a Bárbara Hardi, expresa que "soñamos narrando, enseñamos narrando, recordamos, prevenimos...y vivimos por medio de la narrativa". Más adelante, se refiere y precisa el significado de la narrativa y la vida y el aprendizaje en el currículo de enseñanza. Asimismo, en un área más disímil, el ensayo producto de una investigación Lecturas literarias para la educación física para futuros maestros universitarios en la Universidad de Huelva, de los autores José Antonio Tamayo y Rubén Esquivel Ramos, precisan en su justificación que "...el uso de los nexos históricos y literarios favorecen al conocimiento de la realidad, pues describen y recrean mediante imágenes artísticas una determinada época social o momento histórico..." (2008, p. 3). En el caso peruano, y específicamente de San Marcos, existe una variedad de artículos y textos que se refieren a mejorar el aprendizaje, así discurrimos, por ejemplo, en la investigación "Estrategias didácticas inferenciales en el desarrollo de la comprensión lectora" (Inga, Rojas y Varas, 2015) relacionado sobre lecturas de ensayos por alumnos; otro trabajo de investigación como "El estudio del perfil socioeducativo de medios de los jóvenes que ingresan a la UNMSM" (Frinsancho, 2015), que trata, dentro de otros aspectos, del consumo de medios periodísticos como contribuyentes en forma residual al aprendizaje; aspectos que consideramos loables pero distanciados un tanto de nuestro estudio específico en relación con los estudiantes de economía a través de la narrativa (novelas y cuentos). Sin embargo, debemos destacar que en la investigación bibliográfica se han encontrado muchos estudios referidos a nivel primaria y secundaria sobre el aprendizaje a través de la narrativa, estudios que tienen fines distintos a la opción universitaria materia de nuestro estudio.

\section{Presencia de la narrativa en ensayos históricos y económicos de autores extranjeros y nacionales.}

Iniciamos comentando a dos autores japoneses en la obra Historia del Japón, el primero: SumiiSue, en su novela Hashi no naiKawa aborda la cuestión de los burukumin (los que hacían trabajos impuros relacionados con la muerte: sepultureros). Con esta novela publicada en 1959 se produjo un espacio en el debate 


\section{Pensamiento Crítico Vol. ᄅl, № 2}

público al hacerse pública en noviembre de 1975 la existencia de un libro manuscrito (TokushuBurakuChimeiSokan) que recogía los nombres de asentamientos buraku. Empresas, y también particulares, compraron copias para saber el origen social de los trabajadores o -demasiado a menudo- de los futuros yernos y nueras. Reflejando una suerte de prejuicio social japonés como parte de su arraigo cultural que impacta en los aspectos socioeconómicos, pues podría dar lugar al despido de trabajadores o la marginación familiar (Junqueras y Madrid, 2012, p. 282).

Asimismo, otro autor, Yasuo Tanaka, se refirió en su novela Nantona kuKurisutaru sobre los altos costos de vida en el año 1981, que retrató la vida de los miembros de la clase urbana de la capital, estos eran individuos preocupados por ir a comprar a las caras tiendas de Aoyama, Roppongi y Ginza, sin excesiva preocupación por quienes los rodean; lo que conlleva a reflejar la economía consumista del Japonés a tal punto que desbordaba las relaciones humanas. Es decir, el sentido de su vida circundaba en el consumo cotidiano (Junqueras y Madrid, 2012, p. 283).

En el caso de Francia (Europa) estudiamos a Piketty con su obra El capital del siglo XXI, publicada en 2013, donde podemos apreciar la relación estrecha entre la narrativa y la economía en temas muy puntuales como las desigualdades y la pobreza. En este caso, Piketty se vale de obras narrativas para explicar la economía: Los miserables, de Víctor Hugo, y Papá Goriot, de Balzac, a principios del siglo XIX.

Piketty indica que Los miserables no nació de la imaginación del novelista, sino de la realidad sórdida de la época (Pikkety, 2013, p. 17). Más adelante, sobre el sentido del dinero, francos o libras, y los niveles de ingreso y fortuna de los diferentes personajes, señala que eran relatados para fijar en la mente del lector los estatus sociales y niveles de vida de la época, lo que permitía apreciar las desigualdades de la distribución de la riqueza y los ingresos, lo cual, a percepción del autor economista, refiere épocas de muy bajo crecimiento (Pikkety, 2013, p. 98).

En Papá Goriot, obra célebre de Balzac, alude a dos personajes en lo que se denomina discurso de Vautrin, quien explica al otro personaje estudiante de derecho que el mérito y el trabajo es una ilusión. En particular, le indica los niveles de ingresos anuales a los que podrían acceder en dos alternativas de matrimonio: si se casa con una cortesana, aun formando parte de los graduados en derecho con más méritos entre 


\section{Carlos Armas Morales}

todos los jóvenes de París, tendrá que contentarse con ingreso mediocres y renunciar a la verdadera holgura; pero si es que se casa con una señorita rica, se apoderaría de un patrimonio de un millón de francos. Esto le permitirá gozar, con apenas 20 años, de una renta anual de 50000 francos (5\% de capital) que le produciría alcanzar un nivel de riqueza diez veces superior a la primera alternativa; aludiendo el vivir una vida más holgada a partir de una mejor decisión entre las opciones que tiene. Comenta Pikkety que Balzac no necesitaba convencer a nadie con estadísticas representativas de deciles o percentiles para reflejar la realidad socioeconómica en Francia del siglo XIX.

En el ensayo de autor peruano sobre literatura y derecho, trata de la obra de Ciro Alegría: El mundo es ancho y ajeno ${ }^{1}$. Esta novela se desarrolla en Rumi (una comunidad indígena mestiza), como protagonista no humano junto con los personajes Rosendo Maqui y Amenábar. Por tanto, dicha comunidad era célula social oriunda, agrarista y colectiva que se enfrentó con la sociedad feudal peruana de raigambre colonial, explotadora e individualista. Don Álvaro Amenábar y Roldán fragua un juicio sobre linderos para apropiarse de tierras y convertir a los hombres en braceros de su feudo, en un futuro proyecto de explotación minera. El primer despojo de tierras provoca cierta desintegración en el grupo de comuneros que se desplazan de su sede a Yanañahui, lugar inhóspito que después de mucho trabajo fue convertido en tierras productivas. Ello dio lugar a un segundo despojo, cuando el hacendado vuelve a demandarlos y logra reducir a la servidumbre a los comuneros (Rodríguez, 2003).

Desde el punto de vista social refleja en su narrativa diversas formas de abuso y explotación, despojo de tierras, discriminación al indio, corrupción de la justicia; temas que hasta hoy, aunque de diferente forma, subsisten.

1 No esta demás indicar que José Carlos Mariátegui en su obra Ideología y política, refiere y comenta la crónica novelada de Ernesto Reyna sobre el levantamiento de Atusparia (Prefacio a El Amauta Atusparia), en relación a la protesta contra la conscripción vial en 1925; otra forma de explotación odiosa como el "tributo personal". 


\section{Pensamiento Crítico Vol. ᄅl, № 2}

\section{Relaciones de la economía y la narrativa peruana y su complemento para la enseñanza}

Teniendo en cuenta los tópicos anteriores, insistimos en las relaciones entre la economía y la literatura, sustancia el aporte de la narración literaria en diversos temas de la economía. En muchos casos, la ficción narrativa es más detallista que la realidad histórica acontecida, pues nos enfoca hechos de ficción que han ocurrido en nuestra realidad y que podemos apreciar con mayor cobertura de interpretación, salvando, por supuesto, el hecho de que la narrativa literaria (novela y cuento) es ficción.

En cuanto a los temas de derechos económicos y sociales (rescatado de trabajos de alumnos), estos muestran la variedad de temas que abordan el derecho económico acontecido en nuestra realidad pasada, pero que muchos persisten en la actualidad, aunque de diferentes formas, tal como los aspectos laborales donde se observan condiciones de trabajo inadecuadas, despidos injustos, sueldos diminutos. Desde otro ángulo, también observamos despojos de tierras a los campesinos por los hacendados, que en cierta medida, y respetando las diferencias legales, se podría traducir en el desplazamiento de sus tierras del campesino o amazonense por la inversión extranjera, sin considerar la legislación internacional que los ampara (Convenio 169 OIT).

En relación con la corrupción, se observa desde antaño deshonestidad de jueces cuando se favorece al hacendado sobre el indígena, de tal manera que este, cuando tiene un juicio, él ya sabe de antemano que va a perder, porque conoce la corrupción existente de los jueces. En cuanto a los problemas sociales, tales como la pobreza, desigualdad, inequidad y discriminación social, estos no han desaparecido porque se sigue experimentando en nuestra realidad actual.

En relación con los aspectos públicos, la obra narrativa nos muestra la ausencia del Estado, tema de actualidad que se trata de resolver con la descentralización, entre otras políticas, sin embargo persiste la corrupción del pasado, dado que se tienen cinco presidentes regionales presos, diversos alcaldes y muchos funcionarios procesados por diferentes delitos.

De otro lado, en algunos aspectos coinciden tanto temas andinos como citadinos, tal como los casos de discriminación o desigualdades; el andino en las haciendas y los 


\section{Carlos Armas Morales}

citadinos en los centros laborales de la ciudad. Cabe resaltar que en la narrativa de principio del siglo XXI, se pueden observar problemas diversos que son latentes el día de hoy, como la seguridad pública debido a las extorsiones (El héroe discreto); problemas sobre las consecuencias de la guerra interna de los 80 (Abril rojo); Loreto, de Fernando Ampuero, asume sobre las bandas criminales y las extorsiones en el Callao que podemos extenderlas para todo el país, entre otros que nos permiten ligar las realidades pasadas y presentes expuestas por la ficción narrativa.

De otra parte, destacamos a nuestra autoras de siglo XIX (Flora Tritan y Matto de Turner), que nos muestran situaciones similares, tal como el abuso del trabajo, la desigualdad, la discriminación (caso peculiar de obligar a comprar a los indígenas así no tengan necesidad; que podemos equiparar con lo que hacen actualmente delincuentes colombianos que prestan dinero a ciudadanos peruanos y cuando terminan de pagar, les conminan que pidan prestado nuevamente, así no lo necesiten, y si no quieren el préstamo, los amenazan hasta de muerte). En lo presente esto es atentatorio con la dignidad humana, porque niega la libertad de elección individual (derecho al consumidor), lo que nos permite indicar que la realidad pasada no está muy alejada de la realidad actual a través de los siglos, pues persisten estas anomalías o desajustes sociales que se desarrollan como un hilo conector entre siglos y persisten con otro ropaje. En el siguiente cuadro mostramos las temáticas socioeconómicas de cerca de 15 autores peruanos del siglo XX y XXI: Arguedas, Scorza, Vargas Llosa, Ribeyro, Ciro Alegría, César Vallejo, Bryce Echenique, Reynoso, López Albújar, Congrains, Cueto, Flora Tristán, Matto de Turner, etc. 


\section{Pensamiento Crítico Vol. ᄅl, № 2}

\section{CUADRO 1}

Temáticas económico-sociales encontradas en casos de novelas y cuentos andinos y citadinos

\begin{tabular}{|c|c|c|c|}
\hline Asuntos penales-civiles & Asuntos laborales & Asunto sociales & Asuntos político-públicos \\
\hline $\begin{array}{l}\text { - Tráfico de influencias } \\
\text { - Abigeato } \\
\text { - Despojo de tierras } \\
\text { - Corrupción de jueces } \\
\text { - Soborno } \\
\text { - Enriquecimiento } \\
\text { indebido } \\
\text { - Corrupción de } \\
\text { funcionarios } \\
\text { - Homicidio impune } \\
\text { del gamonal } \\
\text { - Compra-venta } \\
\text { obligada }\end{array}$ & $\begin{array}{l}\text { - Trabajo servil } \\
\text { (servidumbre) } \\
\text { - Trabajo como pago } \\
\text { por ocupar tierras } \\
\text { - Trabajo forzado } \\
\text { - Contrato de trabajo } \\
\text { leonino (enganche) } \\
\text { - Pago o renta } \\
\text { diminuta de trabajo } \\
\text { - Pésimas condiciones } \\
\text { de trabajo } \\
\text { - Despido injusto } \\
\text { - Explotación infantil } \\
\text { - Comida a cambio de } \\
\text { trabajo }\end{array}$ & $\begin{array}{l}\text { - Desigualdad } \\
\text { - Afectación ambiental } \\
\text { (minería) } \\
\text { - Informalidad } \\
\text { - Injusticia } \\
\text { - Pobreza } \\
\text { - Discriminación } \\
\text { - Migración } \\
\text { - Desocupación } \\
\text { - Rebelión de } \\
\text { indígenas } \\
\text { - Justicia popular o } \\
\text { indígena } \\
\text { - Violencia contra la } \\
\text { mujer } \\
\text { - Venta de indígenas } \\
\text { (esclavitud) a cambio } \\
\text { de deudas } \\
\text { - Diferencias sociales }\end{array}$ & $\begin{array}{l}\text { - Ausencia de Estado } \\
\text { - Centralización } \\
\text { - Impuesto abusivo } \\
\text { - Favoritismo de la } \\
\text { autoridad } \\
\text { - Abuso de autoridad } \\
\text { - Contubernio Iglesia- } \\
\text { hacendado } \\
\text { - Represión y violencia } \\
\text { oficial }\end{array}$ \\
\hline
\end{tabular}

A manera residual diremos que en nuestro sílabo actual de enseñanza de derecho económico, existen ausencias notables de temas como los delitos penales económicos, que en la actualidad son materia de mucha importancia para evaluar, dada la corrupción de funcionarios públicos y la delincuencia común que afecta al Estado, las empresas y, desde luego, la economía y la sociedad.

Como corolario integrador, los resultados de la investigación nos muestran que existe una relación interesante entre la realidad pasada y la literatura contada en las novelas y cuentos por nuestros autores peruanos. Asimismo, consideramos que hay una referencia objetiva en considerar el uso de la narrativa para el conocimiento de nuestra realidad nacional y los diversos hechos y derechos económicos en la historia del Perú (aprendizaje-enseñanza), tanto para el curso de derecho económico, historia económica del Perú, entre otros. 


\section{Carlos Armas Morales}

\section{Conclusiones}

1. Muchos autores al hacer narrativa (cuentos y novelas) recurren a la realidad económica y social para reflejarla en sus obras literarias, validando la lectura de estas obras para la comprensión de las relaciones económicas, jurídicas e históricas.

2. En el Perú hay pocos estudios que fundamentan las relaciones de la economía, la realidad nacional, la historia con la literatura; solo los encontramos en forma concisa y suelta, a veces en forma referencial, en los prólogos, publicaciones librescas y periodísticas, donde se ven involucrados temas de derecho económico e historia del Perú.

3. Nadie duda que en el Perú, en los últimos años, los niños de primaria han tenido problemas de aprendizaje de lenguaje, que luego se trasladan a la secundaria y a los primeros ciclos de la universidad, de tal manera que el aplicativo lectura literarias de narrativa permitiría una mayor comprensión de nuestra realidad económica e histórica y, asimismo, podría incentivar a la lectura a algunos alumnos que son poco proclives a ella y reafirmar a los que están acostumbrados a este tipo de lecturas.

4. Si bien hay una predisposición de los alumnos para adecuarse a las lecturas de obras narrativas, son escasos los docentes que aplican este procedimiento con amplitud y profundidad, o como un complemento eficiente en la enseñanza de los cursos inherentes, en el sentido de recomendar leer narrativa (cuentos y novelas) en tópicos específicos de la realidad económica y social que aconteció en el país, pues la gran mayoría prefiere ensayos, lo que es excelente, pero no puede obviarse la narrativa para el aprendizaje.

5. Este tipo de narrativa constituye un referente positivo para comprender la realidad en forma más efectiva y amena, produciendo un impacto diferente de las lecturas de textos o ensayos de acontecimientos reales, que restringen detalles y que solo una narrativa de cuentos o novelas los podrían ofrecer, pues muestra más matices de los sucesos acontecidos, complementando los sucesos reales. 


\section{Pensamiento Crítico Vol. ᄅl, № 2}

6. La lectura de obras predispone también a una buena ortografía y redacción, lo que permite asimilar otras de las posibilidades de la narrativa para afianzar la escritura, que es una necesidad del futuro profesional, más aún cuando se ha eliminado el curso de Lenguaje en todas las escuelas de nuestra facultad.

\section{Referencias Bibliográficas}

Armas, C. (2015). Tópicos de derecho económico y la historia económica del Perú en la narrativa peruana para el aprendizaje. Enfoque multidisciplinario. UNMSM Lima. Informe de Investigación.

Beleván, H (1986). Fuegos Artificiales. Lima: Ediciones Virrey.

Frisancho, A. (2015). Perfil psicoeducativo y consumo de medios de los jóvenes que ingresan a la UNMSM. Lima Vol. 2 No. 117-130.

Álvarez, J. (1987). Literatura y economía en España- El ciego articleBulletinHispanique/ Année 1987/volumen 89/Número 1 /pp313-326. Disponible en: http://persee.fr/doc/ hispa/007-4640_1987_num_89_1_4624.

Gallegos, A. (2014). Literatura y economía: el caso argentino. Cuadernos CILHA vol.15, no.2, Mendoza versión On-line ISSN 1852-9615. Encontrado el 12 de febrero 2015.

Inga, M., Rojas, P. y Varas, F. (2015). Estrategias didácticas inferenciales en el desarrollo de la comprensión lectora. En revista Alma Mater Vol. 2 No. 131-141 UNMSM Lima.

Mariátegui, J. (1967). El artista y la época. Ediciones Populares Obras Completas. Lima: Empresa editora Amauta.

Mariátegui, J. (1976). La novela y la vida. Ediciones Populares Obras Completas. Lima: Empresa editora el Amauta.

Mariátegui, J. (1980). Ideología y Política Ediciones Populares Obras Completas. Lima Empresa editora el Amauta. 


\section{Carlos Armas Morales}

Orillo, W. (1988). Barrios Altos. Lima: Editorial Causachum.

Junqueras, O., y Madrid, V. (2012). Historia del Japón. Economía, política y sociedad. Barcelona: Editorial UOC.

Piketty, T. (2013). El capital en el siglo XXI. México: Fondo de Cultura Económica.

Rodríguez, I. (2003). Literatura y Derecho. Lima: Editorial Universitaria Universidad Ricardo Palma.

Tamayo, J. y Esquivel, R. (2008). Lecturas literarias para la educación física y el deporte. Versión reducida. Huelva: Junta de Andalucía-Consejo de Cultura. 